\title{
Son of SAM: Left ventricular outflow tract obstruction with coexistent mitral stenosis and hypertrophic cardiomyopathy
}

\author{
Tomasz A. Timek, MD
}

\author{
From Spectrum Health, Grand Rapids, Mich \\ Disclosures: Author has nothing to disclose with regard to commercial support. \\ Received for publication Dec 14, 2015; accepted for publication Dec 16, 2015; available ahead of print Jan 12, \\ 2016. \\ Address for reprints: Tomasz A. Timek, MD, Spectrum Health, 100 Michigan Ave NE, Grand Rapids, MI 49503 \\ (E-mail: tomasz.timek@spectrumhealth.org). \\ J Thorac Cardiovasc Surg 2016;151:1049-50 \\ $0022-5223 / \$ 36.00$ \\ Copyright (C) 2016 by The American Association for Thoracic Surgery \\ http://dx.doi.org/10.1016/j.jtcvs.2015.12.033
}

Hypertrophic cardiomyopathy (HCM) is a complex and heterogeneous myocardial disease associated with muscular hypertrophy and varying degrees of left ventricular outflow tract (LVOT) obstruction. Although they represent a minority of the affected population, most surgical patients present with significant and symptomatic outflow tract obstruction from a combination of septal hypertrophy and systolic anterior motion (SAM) of the mitral valve. Septal myectomy has proven to be effective therapy, ${ }^{1}$ with few centers in the world accumulating the breadth of surgical experience reported by the Mayo Clinic. In the current issue of the Journal, Hong and colleagues $^{2}$ draw on their vast surgical volume of more than 2100 myectomies to describe a rare but intriguing association of mitral stenosis and HCM. In the study period extending over 22 years, the authors identified 12 patients with septal hypertrophy and mitral stenosis associated with significant LVOT obstruction (maximum LVOT gradient of $70 \mathrm{~mm} \mathrm{Hg}$ ). On echocardiographic review of this patient cohort, the authors propose 4 different mechanisms of LVOT obstruction when septal hypertrophy and significant mitral stenosis coexist: classic SAM of mitral valve leaflets, SAM at the tip of the mitral leaflet with severe limitation of leaflet motion, septal encroachment toward the LVOT, and calcific leaflet distortion toward the LVOT. In all patients, more than 1 mechanism of obstruction was shown to be at play. All patients underwent septal myectomy and mitral valve replacement with a biologic or mechanical prosthesis with no mortality and resolution of LVOT gradients. The authors advocate a cautious approach to these unusual patients and concurrent myectomy and mitral valve replacement as the best surgical therapy to avoid residual postoperative LVOT gradients. The article carries an important message to alert the reader that significant LVOT obstruction can arise without classic SAM and that preoperative echocardiography should be analyzed carefully in such patients. The Mayo group is to be congratulated for bringing to light these novel mechanisms of outflow obstruction that reflect their vast experience with surgical treatment of HCM.

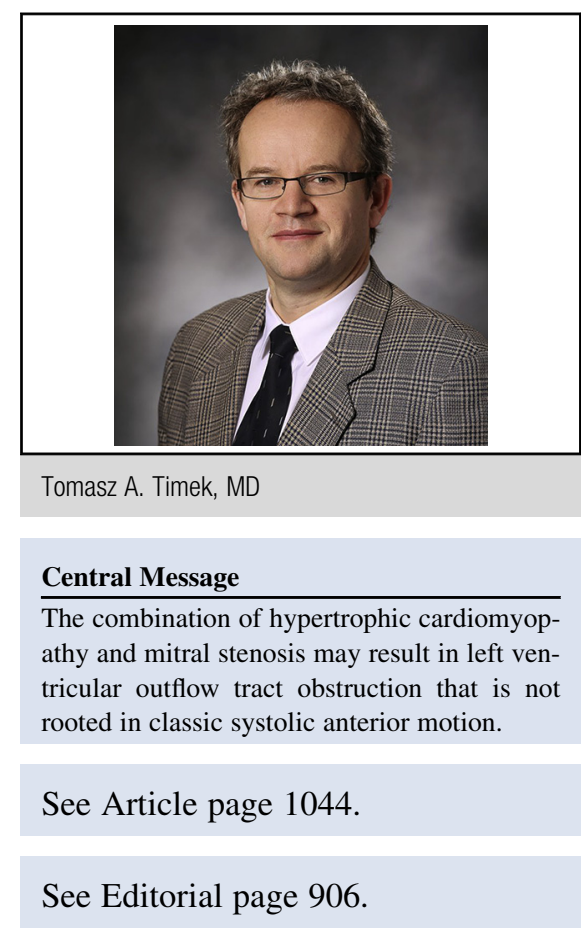

Although the study cohort represents $0.6 \%$ of the surgical HCM population at a specialized referral center, and it is unlikely that a surgeon in routine practice would encounter such a patient more than once in his or her career, the novel mechanisms of LVOT obstruction that arise from concurrent septal hypertrophy and mitral stenosis deserve closer attention. It is noteworthy that the patients in the current study were almost exclusively female (12/13), and most were of advanced age, with a mean age for the entire group of $70 \pm 7.6$ years. Patients undergoing traditional myectomy are significantly younger and have a more balanced gender distribution. ${ }^{3}$ Calcific mitral stenosis is a disease of elderly women; therefore, one may conjecture that it is mitral pathophysiology that is "driving" the LVOT obstruction. The authors do not include septal thickness data in the article but state that the myectomy under these circumstances "may not have to be as extensive as one performed as an isolated procedure." ${ }^{2}$ With this approach, half of the patients received bioprostheses without residual LVOT gradient while obviating the need for anticoagulation in the elderly. Whether mitral valve replacement alone would achieve similar outcomes is unclear. Although the proposed mechanisms of LVOT are distinct, in all patients there was significant overlap of the suspected causes, and because the study population included only 12 patients, the validity 
of such categorization may raise questions. However, it is important to emphasize that only 3 patients had meaningful $(++)$ classic SAM. Leaflet immobility and calcific distortion toward the LVOT, although not characteristic of classic SAM, functionally lead to some anterior displacement of the mitral valve and may be considered related mechanisms. Surgical techniques for septal myectomy continue to evolve and now include transatrial ${ }^{4}$ and minimally invasive ${ }^{5}$ procedures. Mitral valve replacement and septal myectomy were planned a priori in the study patients, and therefore a transatrial approach could have achieved both surgical goals with a single exposure while minimizing morbidity to the ascending aorta and aortic valve, which are associated with transaortic myectomy. Although the authors have achieved excellent results with their traditional approach, they acknowledge this possibility.

The unusual combination of HCM and mitral stenosis presents novel mechanisms of LVOT obstruction that depart from the traditional. The article by Hong and colleagues ${ }^{2}$ is thought provoking and should give surgeons pause when evaluating elderly patients with calcific mitral stenosis and septal asymmetry. The Mayo group challenges us to look deeper into the LVOT and see beyond SAM.

\section{References}

1. Ommen SR, Maron BJ, Olivotto I, Maron MS, Cecchi F, Betocchi S, et al. Longterm effects of surgical septal myectomy on survival in patients with obstructive hypertrophic cardiomyopathy. J Am Coll Cardiol. 2005;46:470-6.

2. Hong J, Schaff HV, Ommen SR, Martin AD, Dearani JA, Nishimura RA. Mitral stenosis and hypertrophic obstructive cardiomyopathy: an unusual combination. J Thorac Cardiovasc Surg. 2016;151:1044-8.

3. Brown ML, Schaff HV, Dearani JA, Li Z, Nishimura RA, Ommen SR. Relationship between left ventricular mass, wall thickness, and survival after subaortic septal myectomy for hypertrophic obstructive cardiomyopathy. J Thorac Cardiovasc Surg. 2011;141:439-43.

4. Gutermann H, Pettinari M, Van Kerrebroeck C, Vander Laenen M, Engelen K, Fret $\mathrm{T}$, et al. Myectomy and mitral repair through the left atrium in hypertrophic obstructive cardiomyopathy: the preferred approach for contemporary surgical candidates? J Thorac Cardiovasc Surg. 2014;147:1833-6.

5. Khalpey Z, Korovin L, Chitwood WR Jr, Poston R. Robot-assisted septal myectomy for hypertrophic cardiomyopathy with left ventricular outflow tract obstruction. J Thorac Cardiovasc Surg. 2014;147:1708-9. 